\title{
Specific Gap Junctions Enhance the Neuronal Vulnerability to Brain Traumatic Injury
}

\author{
Marina V. Frantseva, ${ }^{1}$ Larisa Kokarovtseva, ${ }^{1}$ Christian G. Naus, ${ }^{3}$ Peter L. Carlen, ${ }^{2}$ Derrick MacFabe, ${ }^{4}$ and \\ Jose L. Perez Velazquez ${ }^{1,2}$ \\ 1 The Hospital for Sick Children, Toronto, Ontario, M5G 1X8, Canada, ${ }^{2}$ Department of Medicine (Neurology) and Toronto \\ Western Research Institute, Toronto, Ontario, Canada M5T 2S8, and ${ }^{3}$ Department of Anatomy and Cell Biology, ${ }^{4}$ Clinical \\ Neurological Sciences, University of Western Ontario, London, Ontario, Canada N6A 5C1
}

Traumatic brain injury results in neuronal loss and associated neurological deficits. Although most research on the factors leading to trauma-induced damage focuses on synaptic or ionic mechanisms, the possible role of direct intercellular communication via gap junctions has remained unexplored. Gap junctions connect directly the cytoplasms of coupled cells; hence, they offer a way to propagate stress signals from cell to cell. We investigated the contribution of gap junctional communication (GJC) to cell death using an in vitro trauma model. The impact injury, induced by a weight dropped on the distal CA1 area of organotypic hippocampal slices, results in glutamatedependent cell loss. The gap junctional blockers carbenoxolone and octanol decreased significantly post-traumatic cell death, measured by propidium iodide staining over a $72 \mathrm{hr}$ period after the impact. Dye coupling in the pyramidal layers was enhanced immediately after the injury and decreased over the following $24 \mathrm{hr}$. To determine whether specific connexins were involved in the spread of trauma-induced cell death, we used organotypic slices from connexin43 (Cx43) knock-out mice, as well as acute knock-outs by incubation with antisense oligodeoxynucleotides. Simultaneous knockdown of two neuronal connexins resulted in significant neuroprotection. Slices from the null-mutant $\mathrm{Cx} 43$ mice, as well as the acute $\mathrm{Cx} 43$ knockdown, also showed decreased cell death after the impact. The gap junctional blockers alleviated the traumainduced impairment of synaptic function as measured by electrophysiological field potential recordings. These results indicate that GJC enhances the cellular vulnerability to traumatic injury. Hence, specific gap junctions could be a novel target to reduce injury and secondary damage to the brain and maximize recovery from trauma.

Key words: trauma; gap junctions; antisense; electrophysiology; organotypic slices; cx43 knock-out
Traumatic brain injury results in loss of neurons that have been mechanically damaged as well as other cells that, although not directly damaged, are subjected to a delayed degeneration. This secondary brain damage is attributable to several pathogenic factors, including focal ischemia and ionic fluxes (Hovda et al., 1992; Siesjo, 1993), and is usually preventable. Although most research on trauma-induced cell death focuses on ionic and synaptic mechanisms, the implication of direct intercellular communication via gap junctions has been scarcely explored. Because several intracellular events after traumatic injury result in accumulation of pathogenic factors, the spread of these factors from cell to cell via gap junctions may promote further damage.

Gap junctional communication (GJC) constitutes an important component in direct cell-cell communication that contributes to the maintenance of tissue homeostasis. The gap junctional channels, formed by connexins (Cxs), allow the passage of ions and small molecules (Spray and Dermietzel, 1996). Specifically, Cx26, $\mathrm{Cx} 32, \mathrm{Cx} 47$, and $\mathrm{Cx} 36$ are synthesized in neurons, whereas $\mathrm{Cx} 43$ and Cx30 are found mostly in astrocytes (Dermietzel et al., 1989; Bruzzone et al., 1996; Condorelli et al., 1998; Teubner et al.,

\footnotetext{
Received Aug. 15, 2001; revised Oct. 11, 2001; accepted Oct. 26, 2001.

This work was supported by grants from the Ontario Neurotrauma Foundation (J.L.P.V.) and the Canadian Institutes of Health Research (C.G.N.).

Correspondence should be addressed to J. L. Perez Velazquez, The Hospital for Sick Children, Department of Neurology, Room 6535 Hill Wing, 555 University Avenue, Toronto, Ontario M5G 1X8, Canada. E-mail: jlpv@sickkids.ca. Copyright (C) 2002 Society for Neuroscience $0270-6474 / 02 / 220644-10 \$ 15.00 / 0$
}

2001). Although the biochemical and electrical communication bestowed by gap junctions may play a role during embryonic or fetal development (Trosko et al., 1998) and in the developing nervous system (Bruzzone et al., 1996; Spray and Dermietzel, 1996), their function in mature tissue remains unclear. Experimental evidence indicates that GJC is involved in pathological states and degenerative diseases (Rozental et al. 2000).

Preliminary evidence supporting a role for gap junctions in cellular death has been obtained recently. It was demonstrated that gap junctions exacerbate glial cell death in dissociated cultures when exposed to oxidative stress (Lin et al., 1998). Further recent evidence that GJC is critically involved in tissue injury is provided by the observation that the secondary expansion of infarction is reduced in a rodent model of stroke by blocking gap junctions (Rawanduzy et al., 1997; Saito et al., 1997). The passage of $\mathrm{Na}^{+}$through gap junctions has been shown to propagate cardyomyocyte hypercontracture after ischemic episodes, causing myocardial necrosis (Ruiz-Meana et al., 1999). Blockade of GJC with heptanol limited myocardial necrosis in cardiomyocytes (Garcia-Dorado et al., 1997). Transmission of damage signals via gap junctions, from unhealthy to normal cells, has also been demonstrated in the case of $\alpha$-particle-irradiated cells (Azzam et al. 2001). In addition, a number of observations suggest that gap junctions are altered as a consequence of injuries. Ischemiainduced Cx43 dephosphorylation has been shown in heart (Huang et al., 1999) and brain tissue (Li et al., 1998; Beardslee et al. 2000). In cultures, Cx43 channels open during metabolic 
inhibition (John et al., 1999), which compromises the ability of the cell to maintain the ionic balance.

We used an in vitro trauma model described previously (Adamchik et al. 2000) and present several lines of evidence that GJC promotes cell death after the impact injury. Gap junctional blockers attenuate the extent of cell death, whereas promoting gap junctional communication exacerbates it. To explore the possibility that specific connexins are involved in this process, we used in vitro knockdown of specific connexins as well as $\mathrm{Cx} 43$ knock-out mice. Taken together, the evidence that we present indicates that GJC participates in the trauma-induced cell death.

\section{MATERIALS AND METHODS}

Preparation of organotypic slice cultures. Techniques for culturing brain slices have been described previously (Perez Velazquez et al., 1996, 1997; Adamchik et al., 2000). Briefly, the brains of 7-d-old male Wistar rats, or newborn mice when required, were aseptically removed and immersed in ice-cold dissecting medium, $\mathrm{pH} 7.2$, containing $50 \%$ minimal essential medium (MEM) with no bicarbonate, $50 \%$ calcium and magnesium-free balanced salt solution, $20 \mathrm{~mm}$ HEPES, and $7.5 \mathrm{~mm}$ D-glucose. Hippocampi were dissected and coronal sections obtained $(400 \mu \mathrm{m}$ thickness) using a tissue chopper, and they were then transferred to a dish containing dissecting medium (at room temperature) using the rear end of a glass Pasteur pipette. The slices were then separated carefully with two pairs of fine forceps and transferred to sterile, porous membrane units (0.4 $\mu \mathrm{m}$; Millicell-CM, Millipore, Bedford, MA). The membrane units were placed into six-well trays, each well containing $1 \mathrm{ml}$ of culture medium that was composed of 50\% MEM with Earl's salts and L-glutamine, $25 \%$ balanced salt solution, and $25 \%$ horse serum with 6.5 $\mathrm{mg} / \mathrm{l}$ D-glucose, $20 \mathrm{~mm}$ HEPES buffer, and $50 \mathrm{mg} / \mathrm{ml}$ streptomycinpenicillin. The $\mathrm{pH}$ of the medium was adjusted to 7.2. Cultures were kept in a tissue culture incubator for $7 \mathrm{~d}$ at $37^{\circ} \mathrm{C}\left(5 \% \mathrm{CO}_{2}\right)$ and then at $33^{\circ} \mathrm{C}$ until they were used ( $14 \mathrm{~d}$ in vitro). Cultures were fed three times a week by $50 \%$ medium exchange.

Impact injury. Hippocampal organotypic slice cultures were used after $14 \mathrm{~d}$ in vitro (DIV). The weight-drop injury that we use in our trauma model has been described previously (Adamchik et al., 2000). Briefly, a weight is dropped from a height of $5 \mathrm{~mm}$ on a localized area of the organotypic slice, the distal CA1 area (farther from the CA3 region, near the entorhinal cortex). The characteristics of the weight used are as follows: contact surface, $1.5 \mathrm{~mm}^{2}$; weight, $0.137 \mathrm{gm}$. The location of the impact is easily determined $24 \mathrm{hr}$ after injury, as revealed by propidium iodide (PI) staining detailed in Determination of cell death (see also Figs. 2,7). Control noninjured organotypic slices were placed in separate six-well trays under similar conditions. After the impact injury, slices were placed back in the incubator at $37^{\circ} \mathrm{C}$.

Electrophysiological recordings. For extracellular field potential recordings, slices were transferred to a chamber (Model PDMI-2; Medical Systems Corporation) maintained at $35^{\circ} \mathrm{C}$. Extracellular orthodromic electrical stimulation (100 $\mu \mathrm{sec}$ pulse width) was delivered via a bipolar stimulating enamel-insulated nichrome electrode. An extracellular recording electrode was filled with artificial CSF (ACSF) and placed in the CA1, CA3, or dentate gyrus (DG) cell body layers. Electrical signals were recorded using an Axoclamp 2A amplifier (Axon Instruments, Foster City, CA), with the low-pass filter setting at $1 \mathrm{kHz}$. Data were stored and analyzed using the PCLAMP software (version 6.3, Axon Instruments) via a 12-bit D/A interface (Digidata 1200, Axon Instruments) or filtered at $1 \mathrm{kHz}$, digitized at $88 \mathrm{kHz}$, and stored on videotape using a digital data recorder VR-10 (Instrutech Corporation) for later playback and analysis.

In vitro knock-outs: antisense oligodeoxynucleotide treatment and Western blots. Antisense or missense oligodeoxynucleotides (ODNs) were obtained purified from Medicorp (Montreal, Canada). A total of eight antisense phosphorothioate oligonucleotides were tried for $\mathrm{Cx} 26, \mathrm{Cx} 32$, and $\mathrm{Cx} 43$. Only three of those reduced significantly the level of the respective connexin protein, as judged by Western blots (see below and Fig. 6). The corresponding sequences are as follows: antisense $\mathrm{Cx} 32$, 5'-GTATAGACCTGTCCAGTT-3'; Cx43, 5'-ACTCCAGTCACCCAT3'; Cx26, 5-'CTGTAGTGTGCCCCAATC-3'; missense oligonucleotide, 5-'-GTTTTAATTCCTAAG-3'. To ensure the specificity of the sequences, a BLAST search (NIH web site, www.ncbi.nlm.nih.gov/blast) was performed for each sequence. The ODNs were reconstituted in water to make a stock solution of $2 \mathrm{~mm}$ and then applied to cultures at 30 $\mu \mathrm{M}$ using the liposomal preparation DOTAP (Boehringer Mannheim;
$100 \mu \mathrm{l} / \mathrm{ml}$ ) to improve delivery. Freshly diluted ODN was applied every 12,24 , or $48 \mathrm{hr}$. Optimal results were obtained if applied every 24 or 48 hr for Cx26 and Cx43, and every 48 in the case of Cx32. For the experiments, antisense, missense, or vehicle was applied to the organotypic cultures every $48 \mathrm{hr}$. This treatment did not result in any observable toxicity. We used phosphorothioate backbones in the ODNs because they confer more nuclease resistance. The liposomal preparation was used because it has been shown that using vehicles for delivery reduces the amount of oligomer needed, reduces nonsequence-specific interactions, and protects against nuclease cleavage (Stein, 1998).

Western blotting was used to assess the efficacy of the antisense treatment at reducing specific connexin proteins. Estimation of dye coupling was used to determine the functional efficacy of the antisense treatment (see below). For Western blots, membrane proteins were extracted with Triton X-100 from organotypic slices treated for $5 \mathrm{~d}$ with the oligomers as detailed above. Protein concentration was estimated by the Lowry method (Sigma, St. Louis, MO). Proteins were separated on a $12 \%$ polyacrylamide-SDS gel and electrophoretically transferred to polyvinylidene difluoride membranes (Bio-Rad, Hercules, CA). Blots were blocked for $60 \mathrm{~min}$ in $5 \%$ nonfat dry milk/1\% BSA dissolved in TBST buffer (10 mm Tris, $150 \mathrm{~mm} \mathrm{NaCl,} 0.05 \%$ Tween 20$)$ and then incubated overnight in the presence of specific antibodies for $\mathrm{Cx} 32$, Cx26, or Cx43 (Calbiochem, San Diego, CA) as required. To ensure equality of loading between lanes $(\sim 80 \mu \mathrm{g}$ per lane), an anti- $\alpha$-tubulin antibody (Calbiochem) was used at $0.5 \mu \mathrm{g} / \mathrm{ml}$ to detect the tubulin protein band as shown in Figure 6. The blots were developed using the respective alkaline phosphatase-labeled secondary antibodies (Promega, Madison, WI). The relative optical density (OD) of the respective bands was measured using Quantity One software (Bio-Rad, Mississauga, ON, Canada). The ODs of the connexin bands were normalized to the $\alpha$-tubulin band

Knock-out mice for Cx43. The production of the connexin43 null mutant transgenic mice has been described previously (Reaume et al., 1995). In the experiments described here, genotypes were determined by PCR using primers specific for wild-type $\mathrm{Cx} 43$, or the disrupted $\mathrm{Cx} 43$ gene, as previously described (Reaume et al., 1995; Perez Velazquez et al., 1996). Because the knock-out mice die shortly after birth (2-4 d), organotypic slices were prepared from newborn animals and performed as described above.

Determination of cell death after trauma injury. Organotypic slices were used after 14 DIV. Cell death was determined over a period of $72 \mathrm{hr}$ after injury using the fluorescent viability indicator PI, as described in Adamchik et al. (2000) and Frantseva et al. (1999). PI was applied at 10 $\mu \mathrm{M}$ before the experiments in each dish. PI fluorescence emission was measured immediately before and at 24,48 , and $72 \mathrm{hr}$ after the impact with a $4 \times$ objective, using a confocal microscope (Bio-Rad MRC-600). A rhodamine filter $(510-560 / 590 \mathrm{~nm})$ was used to visualize PI fluorescence emission. Gains and black levels were standardized for each experiment. The fluorescence images were acquired and analyzed with the Comos and Confocal Assistant software packages. Pixel intensity was measured at the three main areas of the hippocampus, CA1, CA3, and dentate gyrus, using a standard size box and the software features.

At the end of each experiment, slices were killed by submerging them in ACSF for $48 \mathrm{hr}$ at low temperature $\left(4^{\circ} \mathrm{C}\right)$ in the presence of PI. The final PI fluorescence obtained after this treatment was considered to be the fluorescence that closely represents $100 \%$ cellular death. Cell death was then expressed as percentage of final fluorescence $\left(F_{\text {fin }}\right)$ minus the background fluorescence $\left(F_{0}\right)$ taken before the injury, as shown in the following equation: \% cell death $=\left(F_{\mathrm{t}}-F_{0}\right) /\left(F_{\text {fin }}-F_{0}\right)^{*} 100$, where $F_{\mathrm{t}}$ is the fluorescence of slices measured at several time points (normally 24, 48, or $72 \mathrm{hr}$ ) after the onset of injury (Frantseva et al., 1999; Adamchik et al., 2000). The statistical comparison between means was performed using the unpaired Student's $t$ test for all experiments described in this study, unless specified otherwise. Statistical significance was set at $p<$ 0.05 . Numerical values are expressed in the figures as mean $\pm \mathrm{SE}$.

Hippocampal slices exhibiting PI staining before trauma or those revealing any incomplete or absent hippocampal layer were excluded from the experiments.

Fluorescence recovery after photobleaching. The extent of dye coupling was estimated using the technique known as fluorescence recovery after photobleaching (FRAP) (Wade et al., 1986; Cotrina et al., 1998; Lin et al., 1998), because this is a very rapid and reliable method to evaluate dye coupling in situ, which is necessary for our experiments. For these experiments, the brain slice is loaded with carboxyfluorescein diacetate, which becomes carboxyfluorescein inside the cells and, because of its 
small molecular weight, crosses gap junctions. Then, a selected area in the pyramidal layers of the hippocampal slice is photobleached using the full-power laser beam of a confocal microscope, and then images are acquired at low power (using neutral density filters) every 1 or 2 min after the photobleaching. The recovery of the fluorescence indicates the extent of gap junctional coupling. It should be noted that part of the fluorescence recovery is also caused by the diffusion of the fluorophore from other areas of the cell that were not bleached, which occurs in the case of neurons that possess long dendritic processes. Controls were performed to determine the recovery caused by passive diffusion of the dye, using slices loaded with fluorescein-dextran, which does not cross gap junctions because of its high molecular weight ( $4000 \mathrm{Da})$. The experiments are detailed in Results (also see Fig. 4).

Organotypic slices were incubated for $1 \mathrm{hr}$ with MEM culture medium containing carboxyfluorescein diacetate $(15 \mu \mathrm{M})$, or fluorescein-dextran when required, and pluronic acid $(0.02 \%)$ to improve intracellular delivery of the dyes. After two to three washes with fresh medium (10 min each) to allow de-esterification of the dye inside cells, selected areas in the pyramidal cell body layers were photobleached with a $3 \times$ zooming to reduce the area of laser scanning (average area bleached was 12,900 \pm $350 \mu \mathrm{m}^{2}$ ). Initially, we acquired a stable baseline fluorescence value that was taken as $100 \%$ to estimate the recovery. Then, the selected area was photobleached, and images were acquired immediately after the photobleaching and at $2 \mathrm{~min}$ intervals for a maximum of $10 \mathrm{~min}$ (see details in Results), using the fluorescein filter of a Bio-Rad MRC600 laser confocal microscope with the confocal aperture to the maximum opening. The fluorescence signal reaches a plateau after 7-8 $\mathrm{min}$ in our system; thus, the intensity value at $10 \mathrm{~min}$ was taken to compute the recovery as percentage of the pre-bleach value. Only well loaded slices were used, which occurred in $\sim 50 \%$ of the slices. Data are presented as percentage of the initial fluorescence emission taken before the photobleaching.

\section{RESULTS}

\section{Effects of altering the strength of gap junctional communication on the extent of cell loss after impact injury}

We used an in vitro impact injury model, which has been described previously (Adamchik et al. 2000). This traumatic injury, induced by a weight dropped from a standard height on the distal CA1 area, results in delayed progressive cell death, which is colocalized with the impact within first $24 \mathrm{hr}$ and spreads throughout the entire slice over 48-72 hr (see Fig. 2). No spatial gradients in cell death over time were clearly distinguished. Our traumatic insult reproduces several of the features found in injuries to the intact brain. For example, in addition to the neuronal and glial loss, as determined by staining with the viability indicator PI (see Figs. 2, 3, 5, 7) or by cresyl violet-stained cell counts (Fig. $1 A$ ), we also observed an increase in glial fibrillary acidic protein (GFAP)-positive cells (Fig. $1 A$ ), which may reflect the known phenomenon of proliferation of astrocytes, termed reactive gliosis, that occurs after traumatic episodes (D'Ambrosio et al., 1999). The glutamate receptor blockers D-AP5 and CNQX significantly ameliorate traumatic cell loss in our model system (Fig. 1A), as well as other well known neuroprotective strategies such as hypothermia (Adamchik et al., 2000). We also observed a drastic reduction of synaptic function immediately after the impact and a partial recovery 24 hr later (Fig. $1 B, C$; Tables 1, 2), similar to the depression of neuronal activity described in brain trauma in vivo (Dixon et al., 1987) as well as weight drop on rat spinal cord [D'Angelo (1973); for a review of electrophysiological consequences of head injury, see Bricolo and Turella (1990)].

To determine whether GJC was partially responsible for the cell loss observed after our traumatic injury, we used two gap junctional blockers, octanol and carbenoxolone (Bani-Yaghoub et al., 1999; Rozental et al., 2001). In preliminary studies, we found dye coupling between Lucifer yellow-filled pyramidal neurons (one of four) (Fig. 3), as well as between glial cells (two of two)

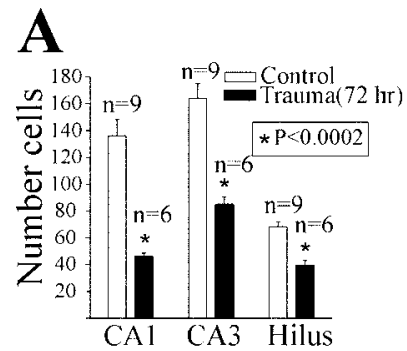

B
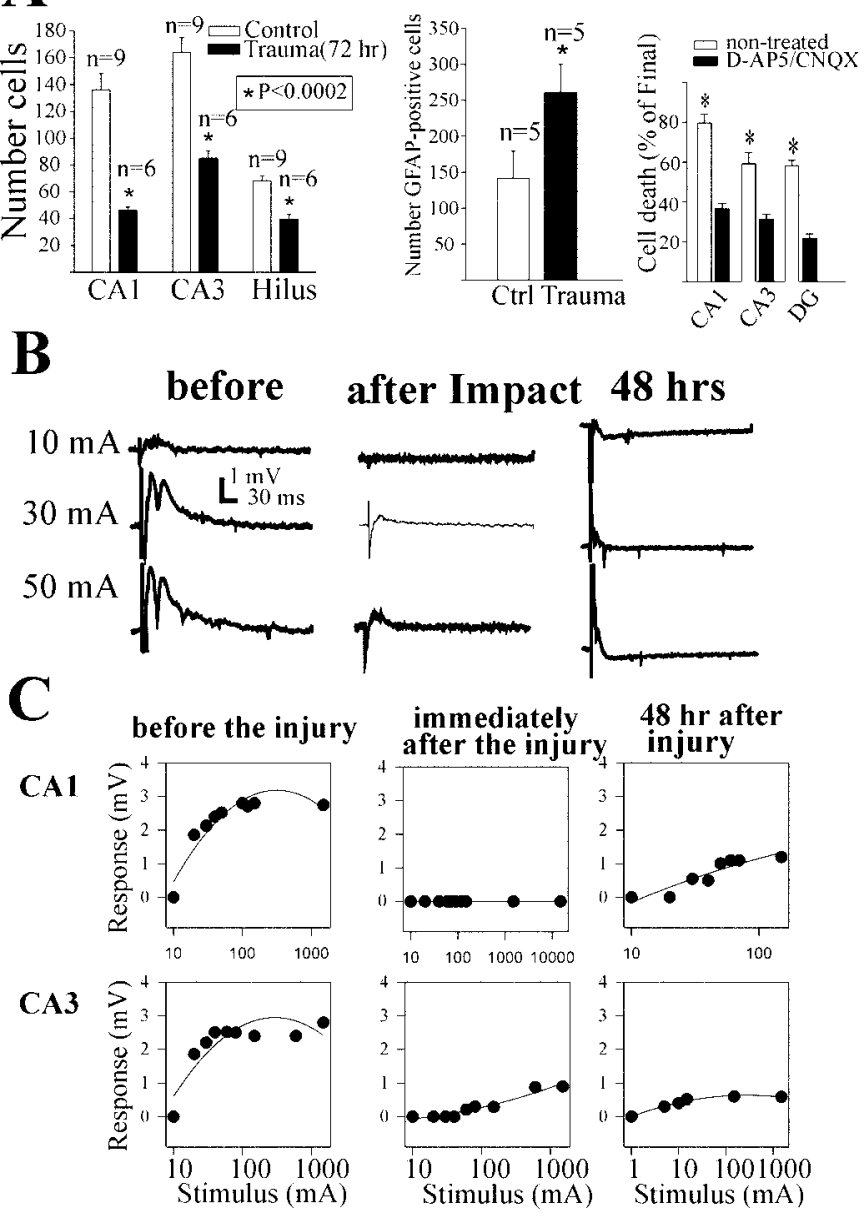

Figure 1. Post-traumatic characteristics of organotypic hippocampal slices. A, Left graph, Number of neurons in three main hippocampal areas, CA1, CA3, and the hilus of the dentate gyrus, $72 \mathrm{hr}$ after the traumatic injury. Slices were stained with cresyl violet. Injured slices presented lower number of neurons in the three regions. Middle graph, The number of GFAP-positive cells (astrocytes) increases after trauma. Slices were stained with an anti-GFAP antibody and visualized using a fluoresceinlabeled secondary antibody. Cell counts were taken from areas of $\sim 50,500$ $\mu \mathrm{m}^{2}$. Right graph, Cell death in the neuronal regions as determined by propidium iodide staining, $72 \mathrm{hr}$ after the impact, in the presence or absence of the glutamate receptor blockers D-AP5 $(20 \mu \mathrm{M})$ and CNQX $(50 \mu \mathrm{M})$. Statistical significance is shown as $p$ values (unpaired Student's $t$ test), comparing injured versus noninjured groups. $B$, Magnitude of the field potential events in response to three stimulating intensities, recorded in the CA1 area, before, 10-20 min, and $48 \mathrm{hr}$ after injury. After the impact, synaptic transmission is greatly reduced and recovers partially $2 \mathrm{~d}$ later. The extracellular stimulation was applied to the Schaffer collaterals. $C$, The input-output responses quantitate the reduction in the field potentials. The graphs represent the amplitude of the postsynaptic potential (as those shown in $B$ ), in millivolts, versus the stimulating intensities. For the recordings in the CA3 area (bottom plot), the extracellular stimulation was applied to the mossy fibers. Note again the partial recovery $2 \mathrm{~d}$ after the impact.

in our organotypic slices. Incubating the organotypic cultures with carbenoxolone $(120-150 \mu \mathrm{M})$ resulted in significant neuroprotection (Figs. 2, 3). Similarly, incubation with octanol $(50 \mu \mathrm{M})$, which has been shown to block GJC in brain tissue (Yuste et al., 1995; Lin et al., 1998; Rozental et al., 2001), resulted in significant neuroprotection: cell death in the CA1-CA2/3 pyramidal layers was $28.1 \pm 4.3 \%$ of that found in injured slices without octanol $(p<0.009 ; n=10)$. To obtain a time window for the neuropro- 


\begin{tabular}{|c|c|c|c|}
\hline & No treatment (48 hr) & CBX $(150 \mu \mathrm{M})$ & CBX no trauma \\
\hline CA1 & $42.8 \pm 16.8 \%$ & $113.3 \pm 13.3 \% *$ & $\begin{aligned} 105.2 & \pm 0.1 \%(\mathrm{PSP}) \\
99.7 & \pm 0.1 \%(\mathrm{PS})\end{aligned}$ \\
\hline CA3 & $77.4 \pm 14.8 \%$ & $80.6 \pm 20.8 \%$ & \\
\hline DG & $70.9 \pm 12.1 \%$ & $68.9 \pm 15.7 \%$ & \\
\hline$n$ & 9 & 8 & 8 \\
\hline
\end{tabular}

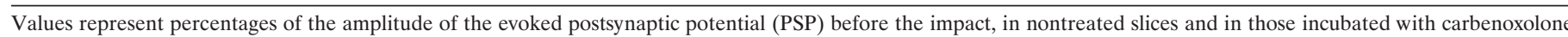

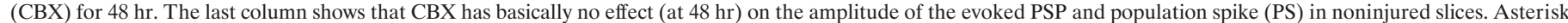
denotes statistical significance $(p<0.008)$.

Table 2. Carbenoxolone improves the maintenance of functional synaptic transmission after impact injury

\begin{tabular}{|c|c|c|c|c|}
\hline & \multicolumn{2}{|c|}{ Immediately after impact } & \multicolumn{2}{|c|}{$48 \mathrm{hr}$ after impact } \\
\hline & Nontreated & $\mathrm{CBX}(120 \mu \mathrm{M})$ & Nontreated & $\mathrm{CBX}(120 \mu \mathrm{M})$ \\
\hline CA1 & $14 / 15$ & $8 / 17$ & $9 / 15$ & $6 / 17$ \\
\hline CA3 & $7 / 15$ & $9 / 17$ & $9 / 15$ & $5 / 17$ \\
\hline DG & $3 / 4$ & $0 / 5$ & $1 / 4$ & $2 / 5$ \\
\hline
\end{tabular}

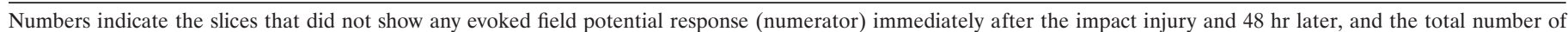

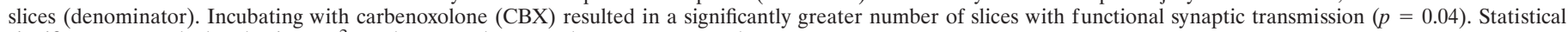
significance was calculated using a $\chi^{2}$ test between the treated versus nontreated group.
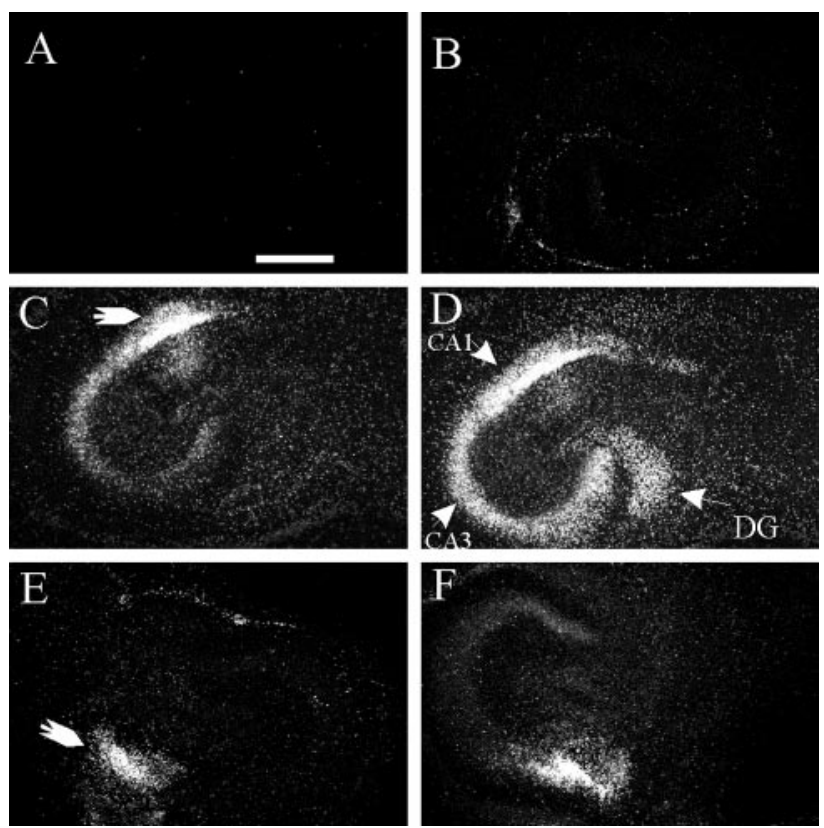

Figure 2. Gap junctional blockers reduce trauma-induced cell death. $A$, $B$, PI fluorescence emission in a control noninjured slice, taken at the same time points as the other two shown below. PI fluorescence $24 \mathrm{hr}(C)$ and $72 \mathrm{hr}(D)$ after the localized impact. Note the spread of cell death through the main hippocampal layers, $C A 1, C A 3$, and $D G$. An arrow in $C$ marks the localized impact. PI emission in a slice $24 \mathrm{hr}(E)$ and $72 \mathrm{hr}(F)$ after the injury, in the continuous presence of the gap junctional blocker carbenoxolone $(120 \mu \mathrm{M})$. The localized impact (visible in $E$ at the bottom left, marked by an arrow) spreads less than other slices where GJC was active $(D)$. For quantitative results, see Figure 3. Scale bar (shown in $A$ ): $500 \mu \mathrm{m}$.

tection observed, carbenoxolone was added at several time points before or after the injury, as shown in Figure 3. Significant neuroprotection, measured over $72 \mathrm{hr}$, was observed if the blocker was added up to $24 \mathrm{hr}$ after the traumatic insult. However, preincubating and removing carbenoxolone 5-10 min after the impact resulted in no neuroprotection (Fig. 3). Adding octanol 2 $\mathrm{hr}$ after the impact also resulted in a significant decrease in cell death, which was $71 \pm 5 \%$ of nontreated slices $(p<0.009 ; n=$ $13)$, although in this case cell death was higher than that found when octanol was present throughout the experiment, as detailed above. We should note that the concentrations of carbenoxolone or octanol used here were nontoxic for our slices. Higher octanol concentrations $(200 \mu \mathrm{M})$ were found toxic for the slice cultures. Although carbenoxolone has been shown to block gap junctions in various systems (Davidson and Baumgarten, 1988; Goldberg et al., 1996; Bani-Yaghoub et al., 1999), it has never been studied in organotypic brain slices. Therefore, we assessed whether carbenoxolone blocked GJC in our system by determination of dye coupling. The extent of dye coupling was estimated using FRAP, a rapid and reliable method to evaluate in situ dye coupling (Wade et al., 1986; Cotrina et al., 1998; Lin et al., 1998). Using this method, we determined that carbenoxolone arrested the fluorescence recovery in the pyramidal layers of the organotypic slice to the same degree as octanol (Fig. 4). As an additional control, we promoted intracellular acidification with propionate (20 mM), a maneuver that closes gap junctions and reduces dye coupling (Perez Velazquez et al., 1994; Rorig et al., 1996; Rozental et al., 2001), and the recovery was similar to that observed in the case of octanol or carbenoxolone (average recovery $10.9 \pm$ $1.5 \% ; n=15)$. Because part of the fluorescence recovery could be caused by the diffusion of the fluorophore from other areas of the cell that were not bleached, we used slices loaded with fluorescein-dextran, which does not cross gap junctions because of its high molecular weight ( $\sim 4000 \mathrm{Da})$, to determine the recovery from passive diffusion. The fluorescence recovery was again similar to that obtained with the three manipulations to block gap junctions, as can be seen in Figure 4. The average reduction of the fluorescence recovery by these manipulations was $59.7 \pm 0.2 \%$ of control untreated slices. Hence, these experiments suggest that $\sim 10 \%$ recovery of the fluorescence may be caused by passive diffusion in our system. This technique is used below to assess GJC after the impact injury; therefore the previous experiments 

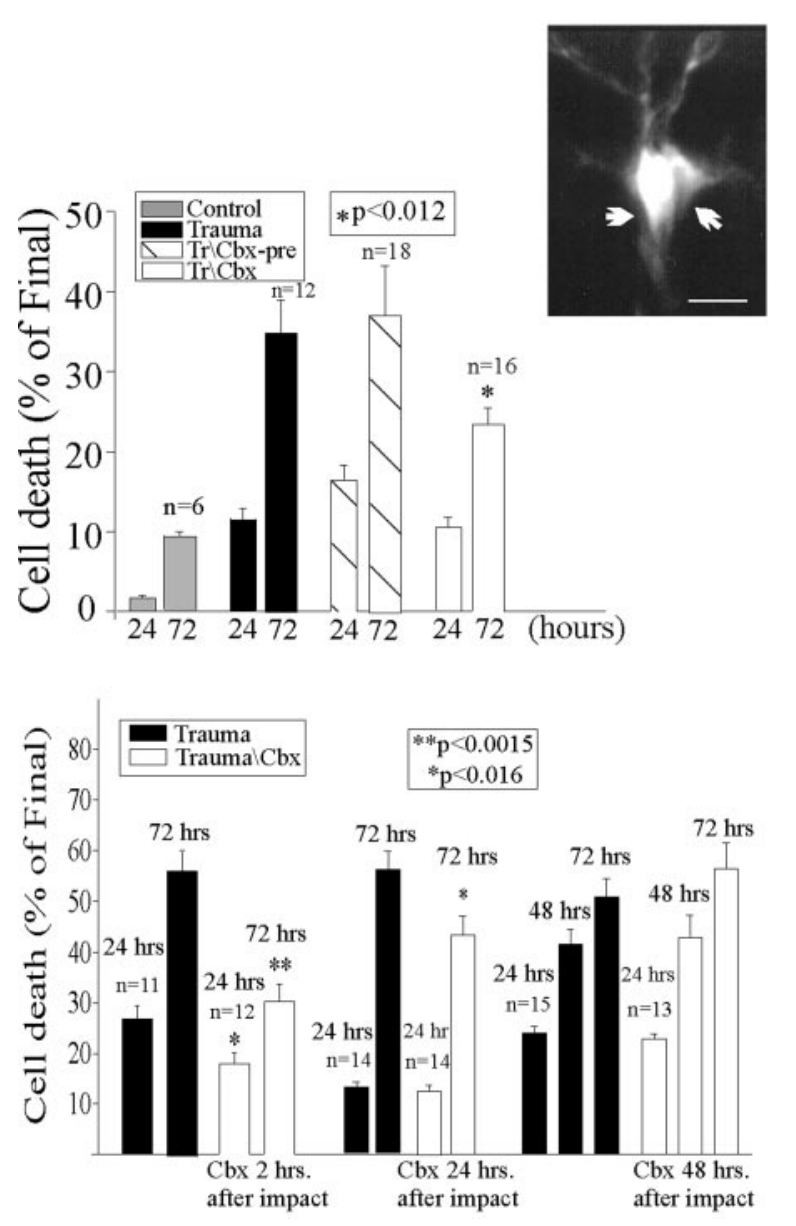

Figure 3. The gap junctional blocker carbenoxolone decreases the spread of post-traumatic cell death. Graphs represent cell death, measured as percentage (mean \pm SE) of maximal cell death (\% of Final; see Materials and Methods for details of the cell death estimation). Top graph, Slices in the continuous presence of $120 \mu \mathrm{M}$ carbenoxolone (Tr|Cbx bars) show less cell death $72 \mathrm{hr}$ after the impact injury. Preincubating and removing the drug 5-10 min after the injury does not result in any appreciable neuroprotection (bars labeled Tr|Cbx-pre). Controls refer to noninjured slices. Inset shows a pair of Lucifer yellow dye-coupled neurons in the CA1 cell layer. Scale bar, $15 \mu \mathrm{m}$. Bottom graph, Adding carbenoxolone 2 and $24 \mathrm{hr}$ after the impact injury (white bars) attenuates cell death measured at 24 and $72 \mathrm{hr}$, as compared with traumatized nontreated slices (black bars). Adding the drug $48 \mathrm{hr}$ after injury does not reduce the cell death observed at $72 \mathrm{hr}$. Statistical significance is shown as $p$ values (unpaired Student's $t$ test), comparing treated versus nontreated groups.

served also as a validation of the FRAP method in the organotypic slices.

If closure of gap junctions decreases the spread of cell death after the traumatic insult, then increased GJC may exacerbate it. To test this hypothesis, we used several agents to alkalinize the intracellular compartment, a manipulation demonstrated to open gap junctions (Spray et al., 1981; Rozental et al., 2001). Trimethylamine $(10 \mathrm{~mm})$ or ammonium chloride $(5-10 \mathrm{~mm})$ was found to be toxic for the organotypic slices. Increased bicarbonate concentration in the culture medium $(60 \mathrm{~mm})$, which is known to cause intracellular alkalinization and promote GJC in brain slices (Church and Baimbridge 1991; Rozental et al., 2001), proved to be nontoxic. As depicted in Figure 5, intracellular alkalinization with $60 \mathrm{~mm}$ bicarbonate enhanced the cell loss as a consequence of the impact in the pyramidal $(145 \%$ of that found in injured
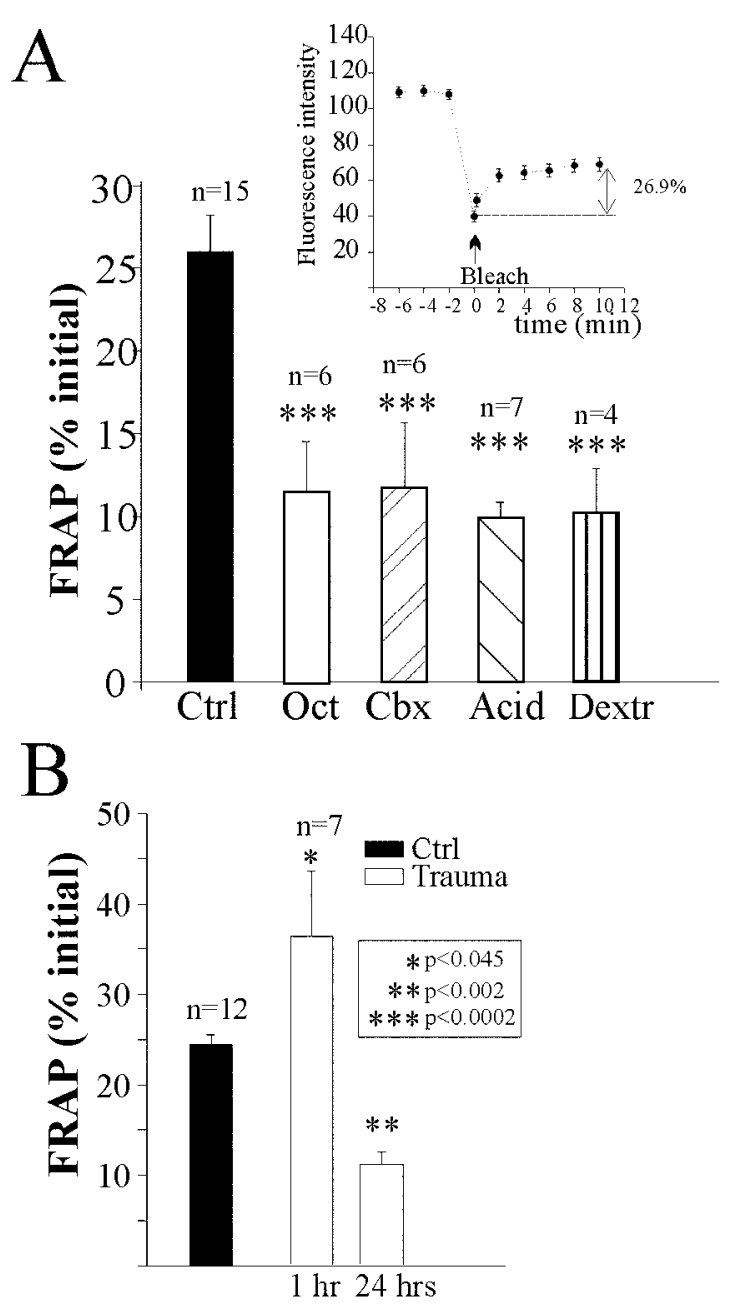

Figure 4. Recovery of fluorescence in the pyramidal cell layers of hippocampal organotypic slices measured by the FRAP method. The average area photobleached was $12,900 \pm 350 \mu \mathrm{m}^{2}$, and the experiments were performed as described in Materials and Methods. $A$, The fluorescence recovery is arrested to the same degree $(\sim 10 \%)$ by the three gap junctional blockers, octanol $(O c t, 0.1 \mathrm{mM})$, carbenoxolone $(C b x, 120 \mu \mathrm{M})$, and intracellular acidification with propionic acid (Acid, $25 \mathrm{~mm}$ ), as compared with recovery in control slices (black bar). As another control, slices were loaded with fluorescein-dextran (bar marked Dextr), which does not cross gap junctions because of its molecular weight, and in this case the recovery is similar to the values obtained with gap junctional blockers, suggesting that this represents background attributable to passive diffusion. Inset graph illustrates the time course of the fluorescence recovery for a typical experiment in a nontreated slice. Photobleach was done at time 0 , and the recovery was estimated at $10 \mathrm{~min} . B$, Recovery is enhanced $\sim 1 \mathrm{hr}$ after the impact injury (middle bar) and reduced after $24 \mathrm{hr}$ (third bar), as compared with control noninjured slices (black bar). For these experiments, a different set of control slices was used. This is why the average value of the recovery $(\sim 25 \%)$ is very close but not equal to that shown in $A$.

nontreated slices $72 \mathrm{hr}$ after the injury; $n=15)$ and dentate granule layers $(141 \% ; n=16)$.

\section{Effects of altering the strength of gap junctional communication on the trauma-induced impairment of synaptic function}

Field potential recordings in the three main hippocampal areas revealed a suppression of synaptic transmission shortly after the impact that recovered partially at $48 \mathrm{hr}$ (Fig. $1 B, C$ ). This reduction was alleviated in the CA1 area if slices were incubated with 


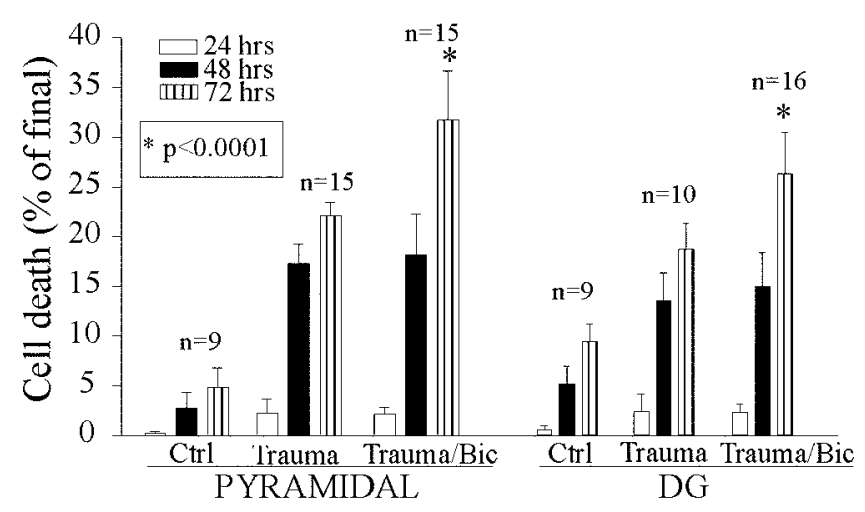

Figure 5. Intracellular alkalinization enhances the extent of the injury. Incubating slices in medium containing $60 \mathrm{~mm}$ bicarbonate (bars labeled Trauma/Bic), which causes intracellular alkalinization and presumably enhances GJC, results in greater cell death in the pyramidal and dentate gyrus $(D G)$ hippocampal areas. Controls $(C t r l)$ refer to noninjured slices in the presence of the high bicarbonate concentration. Statistical significance is shown as $p$ values (unpaired Student's $t$ test), comparing the injured treated versus nontreated group.

carbenoxolone, as shown in Table 1 . The data in Table 1 represent the averages in slices that had evoked responses $48 \mathrm{hr}$ after the impact. However, field potentials in the CA1 or CA3 areas were absent (neither evoked nor spontaneous activity) (Table 2) in $60 \%$ of the slices (9 of 15) and in $25 \%$ in the dentate granule layers (one of four) $48 \mathrm{hr}$ after injury, which indicates a severe impairment of synaptic function. The presence of carbenoxolone resulted in an increased number of slices with functional synaptic transmission, as shown in Table 2. In control noninjured slices, the continuous presence of carbenoxolone for $48 \mathrm{hr}$ did not cause appreciable changes in the amplitudes of postsynaptic potentials (PSPs) or population spikes recorded in the cell body layers (Table 1, third column). The lack of effects of carbenoxolone on the field PSPs recorded in the pyramidal layers of the hippocampus was also found in other studies (Ross et al., 2000). Hence, the functional recovery in the CA1 area in the presence of carbenoxolone cannot be attributed to nonspecific effects of the drug potentiating field PSPs.

The abolition of synaptic transmission after the traumatic injury could be related to the phenomenon of spreading depression, known to occur after ischemic episodes (Nedergaard and Hansen, 1993; Joshi and Andrew, 2001) and concussive brain injury (Katayama et al., 1990). To determine whether a negative shift in the extracellularly recorded voltage (or positive if the electrode is placed in the dendritic layer) occurred immediately after the impact, the weight was dropped on the distal CA1 area while the organotypic slice was in the recording chamber, and the recording electrode was positioned in the CA2/CA3 area. A voltage shift of 5-15 $\mathrm{mV}$ was recorded 2-5 min after the impact. This voltage shift was also seen in the presence of carbenoxolone in $50 \%$ of the slices (17 of 34), whereas without the drug the synaptic depression occurred in $70 \%$ (21 of 30 ).

\section{Dye coupling is enhanced after impact injury}

To assess GJC after the traumatic insult, the incidence of dye coupling was evaluated using the FRAP technique (Wade et al., 1986; Cotrina et al., 1998; Lin et al., 1998), as detailed above. The advantage of this method is that dye coupling can be assessed in situ, which is necessary for our experimental conditions. Organotypic slices were preloaded with fluorescein diacetate as detailed in Materials and Methods, and areas within the pyramidal cell body layers were subjected to photobleaching. Fluorescence was monitored before photobleaching, immediately after, and every 2 min for a maximum of $10 \mathrm{~min}$, because the plateau was reached after 7-8 $\min$ (Fig. $4 A$, inset). The final fluorescence intensity to determine the percentage recovery was that taken at $10 \mathrm{~min}$ after the photobleaching. Dye coupling was significantly increased immediately after the impact injury, and it decreased when measured $24 \mathrm{hr}$ after (Fig. 4B). This indicates that a transient potentiation of GJC occurs after impact injury.

\section{Cell loss is reduced in antisense-treated slices and slices from knock-out mice}

Because carbenoxolone and octanol are not specific for a particular type of gap junction (connexin), we investigated whether specific connexins are responsible for spreading the impactinduced damage. Although it is widely accepted that hippocampal neurons synthesize mostly Cx26, Cx32, and Cx36 (Dermietzel et al., 1989; Spray and Dermietzel, 1996; Nadarajah et al., 1997; Condorelli et al., 1998), we wished to confirm that these connexins were present in our organotypic slices. Immunoreactivity associated with $\mathrm{Cx} 26$ and $\mathrm{Cx} 32$ was observed in the neuronal cell layers, whereas $\mathrm{Cx} 43$ immunoreactivity was present throughout the slice (Y. Adamchik, M. V. Frantseva, J. L. Perez Velazquez, C. J. Thirlwell, and P. L. Carlen, unpublished observations). The Western blots in Figure 6 also substantiate that these three connexins are present in the organotypic slices when the experiments are performed, after 12-16 d in vitro.

To study the possible differential contribution of different connexins to the cell damage observed after the traumatic insult, specific connexins were partially knocked down using antisense oligonucleotides (Fig. 6). First, we obtained biochemical (Fig. 6) and functional evidence that the antisense treatment in fact was reducing GJC. The functional consequence of the less abundant connexins in the antisense-treated slices is a reduced GJC as determined by the FRAP method. Specifically, cotreatment of slices with antisense ODNs for Cx26 and Cx32 simultaneously reduced fluorescence recovery in the pyramidal layers by an average of $44.2 \pm 16 \%(n=8)$, compared with slices treated with the missense ODN $(p<0.0001 ; n=7)$ or nontreated slices $(p<$ 0.016; $n=20$; but incubated with the liposomal vehicle as detailed in Materials and Methods). Hence, the antisense treatment reduces partially the amount of connexin proteins and dye coupling. The possible effects of this reduction on the extent of traumainduced cell death were then investigated. Cell death was significantly less abundant in slices incubated in the presence of antisense oligonucleotides for $\mathrm{Cx} 26$ and $\mathrm{Cx} 32$ simultaneously, or Cx43. Three different sets of experiments were performed for each case; the results of one of these are shown in Figure 7. Treatment with antisense ODNs for Cx26 or Cx32 separately did not produce observable neuroprotection $(n=15)$.

To confirm these results, we used a genetic mouse strain with a null mutation for Cx43 (Reaume et al., 1995). The cellular biophysical and morphological features of the knock-out brains have been reported previously, and no differences were found between the wild-type and mutant neurons and glial cells with respect to biophysical and synaptic properties; as predicted, dye coupling was reduced by $47.6 \%$ in organotypic slices of Cx43-deficient mice as compared with wild-type or heterozygote littermates (Perez Velazquez et al., 1996; S. Fushiki, J. L. Perez Velazquez, D. MacFabe, L. Zhang, C. Kinoshita, J. F. Bechberger, P. L. Carlen, and C. C. G. Naus, unpublished observations). For these experiments, cell death was evaluated in the neocortical region of 

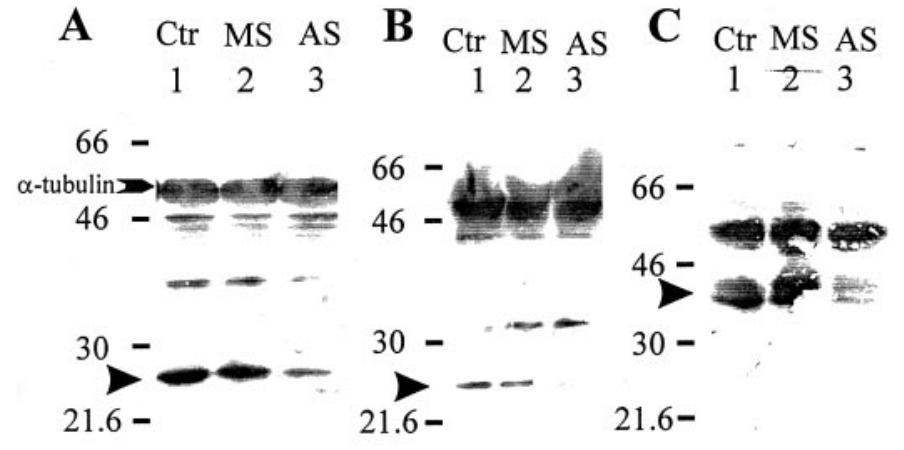

$\mathrm{Cx} 32$

$\mathrm{Cx} 26$

$\mathrm{Cx} 43$

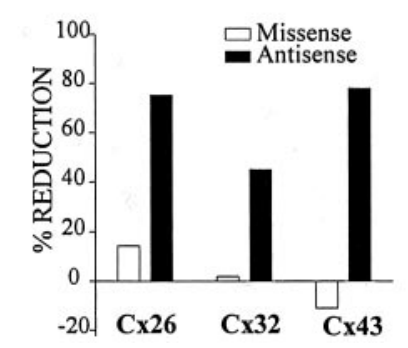

Figure 6. Western blots showing that treatment of organotypic hippocampal slices with antisense ODNs reduces the amount of connexin protein. As described in Materials and Methods, slices were incubated with antisense $(A S$, lane 3$)$ or missense $(M S$, lane 2$)$ oligonucleotides (30 $\mu \mathrm{M})$ for $\mathrm{Cx} 32(A), \mathrm{Cx} 26(B)$, and $\mathrm{Cx} 43(C)$. Lane 1 (Ctr) was loaded with control samples from nontreated slices, incubated with the vehicle used to improve delivery of the ODNs. Numbers at left indicate the position of the molecular weight markers. $\alpha$-Tubulin was used as the control protein to account for the amount of protein loaded in each gel lane $(\sim 80 \mu \mathrm{g})$. The Western blots were performed using antibodies against the specific $\mathrm{Cx}$ and another antibody against tubulin. An arrow indicates the position of the band representing the specific $\mathrm{Cx}$; note that for $\mathrm{Cx} 32$ the band is at $\sim 27 \mathrm{kDa}$, as observed by others and specified by the manufacturer. Bottom graph, Quantification revealed that the OD of the $\mathrm{Cx}$ bands, normalized to the $\alpha$-tubulin band and taking $100 \%$ of the OD of the $\mathrm{Cx}$ band in the control lane (lane 1), was lower in antisense-treated slices than in the control or the missense-treated slices.

the cultured organotypic slices, and the traumatic injury was applied in the middle of the cortex. This was performed because of the small size of the hippocampal formation in newborn animals. Cell death was significantly lower in slices from $\mathrm{Cx} 43$ knock-out animals $24 \mathrm{hr}$ after the impact as compared with wild-type and heterozygote littermates (Fig. 8). Heterozygote mice synthesize $\mathrm{Cx} 43$ to a level that we did not determine. Thus, these data further suggest that GJC plays an important role in determining trauma-induced cell injury.

\section{DISCUSSION}

We have used an in vitro trauma model to study the contribution of GJC to the impact-induced cell death. Using a combination of pharmacological manipulations to reduce or enhance GJC, as well as molecular biological methods to knock down specific connexins, we present converging evidence for a role of GJC between neurons (mediated by $\mathrm{Cx} 32$ and $\mathrm{Cx} 26$ ), as well as between glial cells ( $\mathrm{Cx} 43$ mediated), in promoting trauma-induced cell loss.

Our trauma model (Adamchik et al., 2000) reproduces many of the features of head injury in man and in vivo experiments. Necrotic and apoptotic neuronal death dependent on glutamate receptor activation has been extensively documented after
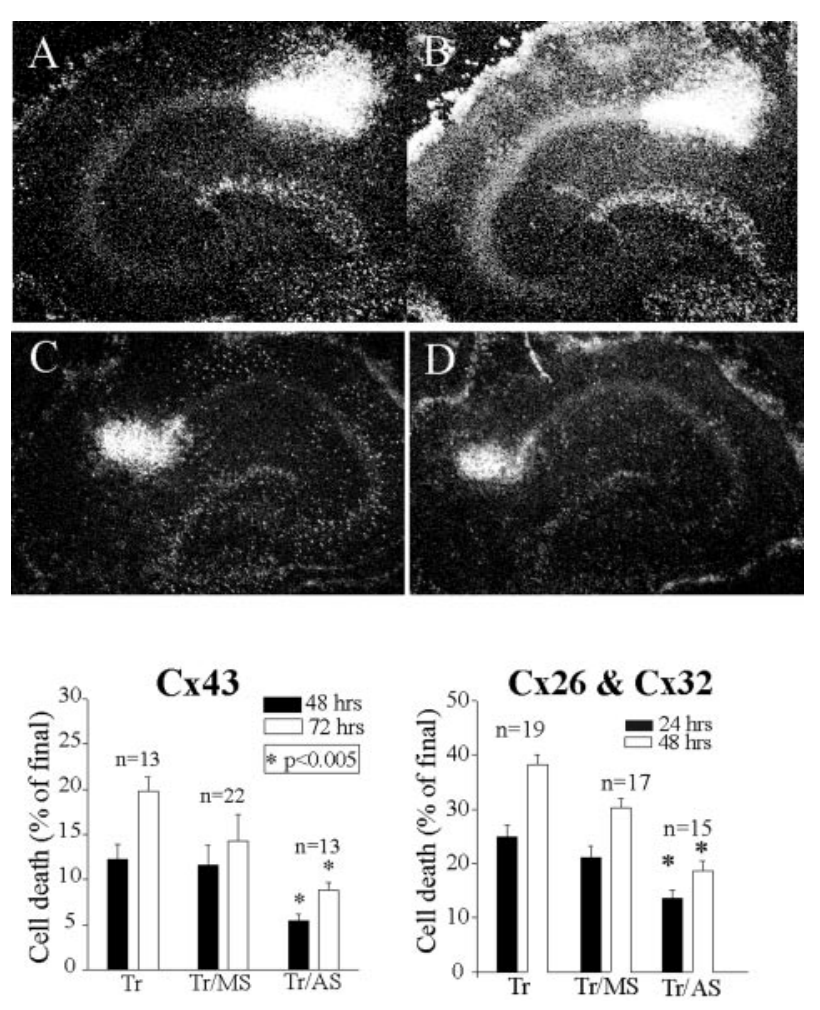

Figure 7. Reduction of GJC by antisense treatment results in decreased post-traumatic cell death. $A, B$, PI fluorescence in a slice incubated in the presence of the missense ODN $(30 \mu \mathrm{M}), 24$ and $70 \mathrm{hr}$ after the localized impact injury (visible at the top right corner as the area of intense fluorescence emission). $C, D$, Slice incubated in the presence of antisense ODN for $\mathrm{Cx} 43(30 \mu \mathrm{M})$ at same time points as the other. Note the reduced PI fluorescence, except in the area where the weight was dropped. Bottom bar graphs show the quantitation of the PI fluorescence for slices treated with antisense ODNs (bars labeled $\operatorname{Tr} / A S$ ) for $\mathrm{Cx} 43$ (left graph) or Cx32 and $\mathrm{C} \times 26$ simultaneously (right graph). Slices treated with antisense oligonucleotides have less cell death after the impact injury as compared with slices incubated with the vehicle used to improve delivery of the oligonucleotides (bars labeled $T r$ ) or slices incubated in the presence of missense oligonucleotides $(\operatorname{Tr} / M S)$. Treatment with antisense ODNs for Cx26 or Cx32 separately did not produce a significant effect (data not shown). Statistical significance is shown as $p$ values (unpaired Student's $t$ test), comparing the control injured group $(\operatorname{Tr})$ versus the ODN-treated groups.

trauma injury (Cortez et al., 1989; Lowenstein et al., 1992; Siesjo, 1993; O'Dell et al., 2000). Interestingly, our weight-drop trauma results in a significant cell loss also in the non-neuronal areas of the slices, as well as an increased number of GFAP-positive cells, probably reflecting the proliferation of astrocytes characteristic of the trauma-induced reactive gliosis (D'Ambrosio et al., 1999). We also observed a reduction of synaptic function immediately after the impact, which correlates with the depressed neuronal activity found in head trauma (Dixon et al., 1987; Bricolo and Turella, 1990). Increased GJC was found a short time after the injury in our slices, as determined by the FRAP experiments. Similarly, enhanced GJC after injuries has been demonstrated in other systems, after hyposmotic shocks in mouse astrocytes (Scemes and Spray, 1998) and after axotomy in motor neurons (Chang et al. 2000). Other studies showed that connexin channels open during metabolic inhibition (John et al., 1999), which presumably occurs after trauma, as inferred by the reduction in ATP levels (Sullivan et al., 1998). Although the situation is obviously more complex in the case of injuries to the intact brain, in vitro models 


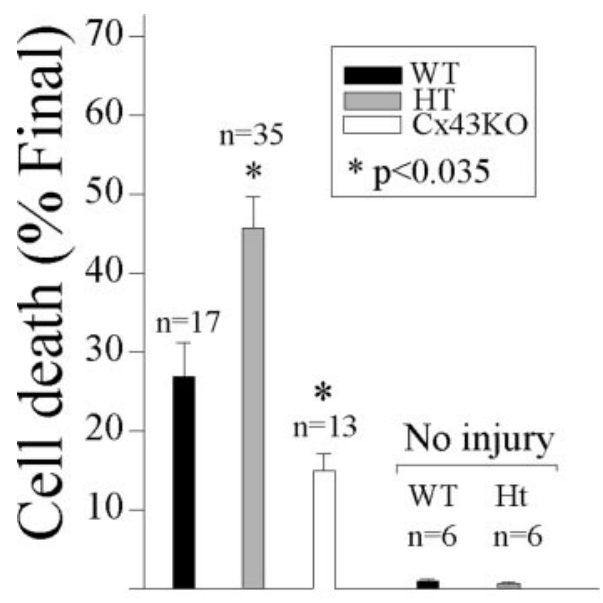

Figure 8. Reduction in post-traumatic cell death in organotypic neocortical slices from Cx43 knock-out mice. PI fluorescence measured at $24 \mathrm{hr}$ indicated less cell death in knock-out slices (white bars) compared with slices from wild-type ( $W T$ ) or heterozygote $(H T)$ littermates. The last two bars represent cell death in control, noninjured slices.

offer a more controllable environment in which specific cellular events can be assessed that are unfeasible using in vivo models. For example, as shown here, we can follow the extension of cell death at several time points in the same brain slice.

The observations that gap junctional blockers attenuate to some extent the impact-induced cell loss whereas promoting GJC (by intracellular alkalinization) exacerbates the spread of the injury, indicates that the initial enhancement of GJC shortly after the injury, which was found in the FRAP experiments, may be involved in spreading stress factors from cell to cell, which results in expansion of the injury. Although the amplified GJC immediately after injuries is a short-term effect, long-term changes in gap junctions have also been documented in various systems. Along these lines, an increased synthesis of the neuronal Cx26 was found after crush injury (Nagaoka et al., 1999), as well as of Cx43 after facial nerve transection (Rohlmann et al., 1994), whereas a decreased Cx32 mRNA presence has been shown after sciatic nerve transection (Chandross et al., 1996). Recent experiments have also demonstrated that GJC between astrocytes is disrupted in human brain trauma (Castejon, 1998). These alterations in protein expression and GJC may be involved in the long-term consequences of the injury. Several other injury-induced changes in gap junctions have been described (for review, see Chandross, 1998).

The pathophysiology of traumatic injury is thought to consist of a phase of cell loss caused by the direct impact and mechanical disruption of tissue and a secondary phase that consists of molecular and cellular events that appear hours to days after the impact. Gap junctions could facilitate the spread of stress factors between coupled cells, as shown in the case of the transmission of damage signals in $\alpha$-particle-irradiated coupled cells (Azzam et al. 2001) and in propagating apoptotic glial cell death after oxidative stress, calcium ionophores, or metabolic inhibition (Lin et al., 1998). As to what factors may be spreading through the gap junctions, these may include sodium or calcium ions, apoptotic factors (Lin et al., 1998), lysophospholipids, or $\mathrm{IP}_{3}$. Specifically, $\mathrm{IP}_{3}$ has been implicated in delayed cell death (Khan et al., 1996), and there is recent evidence that $\mathrm{IP}_{3}$-mediated signaling is enhanced a few hours after traumatic injury in an in vitro model (Weber et al., 2001). Small pathogenic molecules diffusing from unhealthy to healthy cells could result in cell death that is maximal near the site of injury and decreases toward the periphery. Alternatively, spread of sodium or calcium ions could depolarize a large number of neurons/glia, thus immediately involving the whole circuitry, enhancing glutamate release and injury propagation, and resulting, most probably, in more uniform damage. No evidence was obtained for spatial gradients of cell death, either in control or in carbenoxolone-treated slices. We speculate that GJC increases the cellular vulnerability to injuries and amplifies excitotoxic components that represent an important contribution to the damage, as revealed in our experiments and those of others (Siesjo, 1993).

The observed impairment of synaptic function could be caused by specific synaptic mechanisms or cell loss. Our studies do not address this issue, but it is clear that the tissue is functionally compromised for a long-term period after the initial injury. It is therefore reasonable to propose that cell loss is involved, in part, in this impairment, although disruption of calcium (Weber et al., 2001) and of synaptic homeostasis (Sullivan et al., 1998), as well as the impairment of glial potassium regulation that occurs in post-traumatic hippocampus (D'Ambrosio et al., 1999), may also play an important role in this phenomenon. Considering that spreading depression (SD) occurs in nervous tissue after ischemic or traumatic episodes (Katayama et al., 1990; Nedergaard and Hansen, 1993; Joshi and Andrew, 2001) and is associated with cell death if the tissue is metabolically compromised (Obeidat and Andrew, 1998) and that gap junctional blockers arrest this depression and reduce infarct volume in an in vivo stroke model (Rawanduzy et al., 1997; Saito et al., 1997), it is possible that the initial SD that we measured a short time after the impact could be involved in the delayed cell death. However, the observations that carbenoxolone and octanol are neuroprotective even when administered a long time after the impact injury suggests that there may be other mechanisms in addition to the initial depolarizing wave, because SD is unlikely to occur over a prolonged period of time. Interestingly, the presence of carbenoxolone alleviates the synaptic impairment mostly in the CA1 layer, probably because this area is most damaged directly by the impact.

One of the foremost problems in gap junction research is that there are no connexin-specific blockers, or drugs in general, and the manipulations to open or close gap junctions will affect all kinds (Rozental et al. 2001). In an attempt to determine whether specific connexins, or gap junctional pathways, were involved in spreading trauma-induced cell death, we used a genetic mouse model with a null mutation for the astrocytic Cx43 (Reaume et al., 1995; Bruzzone et al., 1996; Spray and Dermietzel, 1996), as well as in vitro knock-outs using antisense ODNs. At the developmental stage in which we use our slices, both $\mathrm{Cx} 26$ and $\mathrm{Cx} 32$ are present in neurons (Dermietzel et al., 1989; Nadarajah et al., 1997), as confirmed by our Western blots and immunohistochemistry on the organotypic slices. It is therefore not surprising that a simultaneous knockdown of both connexins is needed to appreciate a neuroprotective effect, because we did not find any effects when these connexins were knocked down separately. Also, diminishing glial connectivity (antisense for $\mathrm{Cx} 43$ or the mice knock-out experiments) was sufficient to reduce the impactinduced cell loss. These results indicate that a partial decrease in neuronal or glial GJC is enough to reduce the secondary damage, whatever the stress signal or specific cascades that may be involved.

The possible role of GJC in promoting or decreasing injury can find justification depending on the point of view. For example, 
GJC could be reasoned to be neuroprotective because glial cells will remove potassium efficiently, and therefore neurons will not be subjected to large depolarizations with the consequent excitotoxicity (Blanc et al., 1998). On the other hand, it can be reasoned that metabolic stress factors pass through gap junctions, and the wide spread of potassium and calcium waves through coupled astrocytes promotes the release of glutamate from these cells and therefore causes more excitotoxicity far from the focus. Which factor will predominate is hard to determine in a complex neuronal-glial network. It is entirely possible that, under some conditions, an enhanced GJC is neuroprotective, as evidenced in the case of ischemic insults to gastric mucosa (Iwata et al., 1998) or in some rodent stroke models (Siushansian et al., 2001).

In summary, our data have revealed a possible novel target to prevent the spread of trauma-induced injury. As shown in these studies, pharmacological or molecular manipulations that reduce GJC significantly decrease the extent of post-traumatic cell death, although none of these treatments cause a complete $(100 \%)$ neuroprotection. Many other factors are obviously involved in spreading the injury, and we have now gathered evidence for the relative contribution of direct intercellular coupling. These observations may provide valuable information about possible therapeutic strategies to arrest the spread of the injury, using, for example, connexin-specific tools such as anti-connexin antibodies (Rozental et al., 2001), thereby reducing injury and secondary damage to the brain and maximizing recovery from trauma injury.

\section{REFERENCES}

Adamchik Y, Frantseva MV, Weisspapir M, Carlen PL, Perez Velazquez JL (2000) Methods to induce primary and secondary traumatic damage in organotypic hippocampal slice cultures. Brain Res Protoc 5:153-158.

Azzam EI, de Toledo SM, Little JB (2001) Direct evidence for the participation of gap-junction mediated intercellular communication in the transmission of damage signals from alpha-particle irradiated to nonirradiated cells. Proc Natl Acad Sci USA 98:473-478.

Bani-Yaghoub M, Underhill TM, Naus CCG (1999) Gap junction blockade interferes with neuronal and astroglial differentiation of mouse P19 embryonal carcinoma cells. Dev Genet 24:69-81.

Beardslee MA, Lerner DL, Tadros PN, Laing JG, Beyer EC, Yamada KA, Kleber AG, Schuessler, Saffiz JE (2000) Dephosphorylation, intracellular redistribution of Connexin43 during electrical uncoupling induced by ischemia. Circ Res 87:656-662.

Blanc EM, Bruce-Keller AJ, Mattson MP (1998) Astrocytic gap junctional communication decreases neuronal vulnerability to oxidative stress-induced disruption of calcium homeostasis and cell death. J Neurochem 70:958-970.

Bricolo AP, Turella GS (1990) Electrophysiology of head injury. In: Handbook of clinical neurology (Braakman R, ed), pp 181-206. New York: Elsevier.

Bruzzone R, White TW, Paul DL (1996) Connections with connexins: the molecular basis of direct intercellular signaling. Eur J Biochem 238:1-27.

Castejon OJ (1998) Morphological astrocytic changes in complicated human brain trauma. A light and electron microscopic study. Brain Inj 12:409-427.

Chandross KJ (1998) Nerve injury and inflammatory cytokines modulate gap junctions in the peripheral nervous system. Glia 24:21-31.

Chandross KJ, Kessler JA, Cohen RI, Simburger E, Spray DC, Bieri P, Dermietzel R (1996) Altered connexin expression after peripheral nerve injury. Mol Cell Neurosci 7:501-518.

Chang Q, Pereda A, Pinter MJ, Balice-Gordon RJ (2000) Nerve injury induces gap junctional coupling among axotomized adult motor neurons. J Neurosci 20:674-684.

Church J, Baimbridge KG (1991) Exposure to high $\mathrm{pH}$ medium increases the incidence and extent of dye coupling between rat hippocampal CA1 pyramidal neurons in vitro. J Neurosci 11:3289-3295.

Condorelli DF, Parenti R, Spinella F, Salinaro AT, Belluardo N, Cardile V, Cicirata F (1998) Cloning of a new gap junction gene (Cx36) highly expressed in mammalian brain neurons. Eur J Neurosci 10:1202-1208.

Cortez SC, McIntosh TK, Noble LJ (1989) Experimental fluid percussion brain injury: vascular disruption and neuronal and glial alterations. Brain Res 482:271-282.
Cotrina ML, Kang J, Lin H-C, Bueno E, Hansen TW, He L, Liu Y, Nedergaard M (1998) Astrocytic gap junctions remain open during ischemic conditions. J Neurosci 18:2520-2537.

D'Ambrosio R, Maris DO, Grady MS, Winn HR, Janigro D (1999) Impaired $\mathrm{K}^{+}$homeostasis and altered electrophysiological properties of post-traumatic hippocampal glia. J Neurosci 19:8152-8162.

D'Angelo CM (1973) The H-reflex in experimental spinal cord trauma. J Neurosurg 2:791-805.

Davidson JS, Baumgarten JM (1988) Glycyrrhetinic acid derivatives: a novel class of inhibitors of gap junctional intercellular communication. Structure-activity relationship. J Pharmacol Exp Ther 246:1104-1107.

Dermietzel R, Traub O, Hwang TK, Beyer E, Bennett MVL, Spray DC, Willecke K (1989) Differential expression of three gap junctional proteins in the developing and mature brain tissue. Proc Natl Acad Sci USA 86:10148-10152.

Dixon CE, Lyeth BG, Povlishock JT, Findling RL, Hamm RJ, Marmarou A, Young HF, Hayes RL (1987) A fluid percussion model of experimental brain injury in the rat. J Neurosurg 67:110-119.

Frantseva MV, Carlen PL, El-Beheiry H (1999) A submersion method to induce hypoxic damage in organotypic hippocampal cultures. J Neurosci Methods 89:25-31.

Garcia-Dorado D, Inserte J, Ruiz-Meana M, Gonzalez MA, Solares J, Julia M, Barrabes JA, Soler-Soler J (1997) The gap junctional uncoupler heptanol prevents cell-to-cell progression of hypercontracture and limits necrosis during myocardial reperfusion. Circulation 96:3579-3586.

Goldberg GS, Moreno AP, Bechberger JF, Hearn SS, Shivers RR, MacPhee DJ, Zhang YC, Naus CCG (1996) Evidence that disruption of connexin particle arrangements in gap junctional plaques is associated with inhibitors of gap junctional communication by a glycyrrhetinic acid derivative. Exp Cell Res 222:48-53.

Hovda DA, Becker DP, Katayama Y (1992) Secondary injury and acidosis. J Neurotrauma 9:S47-S60.

Huang XD, Sandusky GE, Zipes DP (1999) Heterogeneous loss of connexin 43 protein in ischemic dog hearts. J Cardiovasc Electrophysiol 10:79-91.

Iwata F, Joh T, Ueda F, Yokoyama Y, Itoh M (1998) Role of gap junctions in inhibiting ischemia-reperfusion injury of rat gastric mucosa. Am J Physiol 275:G883-G888.

John SA, Kondo R, Wang SY, Golhaber JI, Weiss JN (1999) Connexin43 hemichannels opened by metabolic inhibition. J Biol Chem 274:236-240

Joshi I, Andrew RD (2001) Imaging anoxic depolarization during ischemia-like conditions in the mouse hemi-brain slice. J Neurophysiol 85:414-424.

Katayama Y, Becker DP, Tamura T, Hovda DA (1990) Massive increases in extracellular potassium and the indiscriminate release of glutamate following concussive brain injury. J Neurosurg 73:889-900.

Khan AA, Soloski MJ, Sharp AH, Schilling G, Sabatini DM, Li S, Ross CA, Snyder SH (1996) Lymphocyte apoptosis: mediation by increased type 3 inositol 1,4,5-triphosphate receptor. Science 273:503-507.

Li WEI, Ochalski PAY, Hertzberg EL, Nagy JI (1998) Immunorecognition, ultrastructure and phosphorylation status of astrocytic gap junctions and connexin 43 in rat brain after cerebral focal ischemia. Eur J Neurosci 10:2444-2463.

Lin JH-C, Weigel H, Cotrina ML, Liu S, Bueno E, Hansen AJ, Hansen TW, Goldman S, Nedergaard M (1998) Gap-junction-mediated propagation and amplification of cell injury. Nat Neurosci 1:494-500.

Nadarajah B, Jones AM, Evans WH, Parnavelas JG (1997) Differential expression of connexins during neocortical development and neuronal circuit formation. J Neurosci 17:3096-3111.

Nagaoka T, Oyamada M, Okajiama S, Takamatsu T (1999) Differential expression of gap junction proteins connexin26, 32 and 43 in normal and crush-injured rat sciatic nerves. Close relationship between connexin43 and occludin in the perinerium. J Histochem Cytochem 47: 937-948.

Nedergaard M, Hansen AJ (1993) Characterization of cortical depolarizations evoked in focal cerebral ischaemia. J Cereb Blood Flow Metab 13:568-574.

Obeidat AS, Andrew RD (1998) Spreading depression determines acute cellular damage in the hippocampal slice during oxygen/glucose deprivation. Eur J Neurosci 10:3451-3461.

O’Dell DM, Raghupathi R, Crino PB, Eberwine JH, McIntosh TK (2000) Traumatic brain injury alters the molecular fingerprint of TUNEL-positive cortical neurons in vivo: a single-cell analysis. J Neurosci 20:4821-4828.

Perez Velazquez JL, Valiante TA, Carlen PL (1994) Modulation of gap junctional mechanisms during calcium-free induced field burst activity: a possible role for electrotonic coupling in epileptogenesis. J Neurosci 14:4308-4317.

Perez Velazquez JL, Frantseva M, Bechberger JF, Naus CGC, Juneja SC, Velumian A, Carlen PL, Kidder GM, Mills LR (1996) Development of astrocytes and neurons in cultured brain slices from mice lacking connexin 43. Dev Brain Res 97:293-296.

Perez Velazquez JL, Frantseva MV, Carlen PL (1997) In vitro ischemia 
promotes free radical generation and intracellular calcium accumulation in pyramidal neurons mediated by glutamatergic transmission. J Neurosci 17:9085-9094.

Rawanduzy A, Hansen A, Hansen TW, Nedergaard M (1997) Effective reduction of infarct volume by gap junction blockade in a rodent model of stroke. J Neurosurg 87:916-920.

Reaume A, De Souza PA, Kulkarni S, Cargille BC, Zu D, Davies TC, Junega S, Kidder GM, Rossant J (1995) Cardiac malformation in neonatal mice lacking connexin43. Science 267:1831-1834.

Rohlmann A, Laskawi R, Hofer A, Dermietzel R, Wolff JR (1994) Astrocytes as rapid sensors of peripheral axotomy in the facial nucleus of rats. NeuroReport 5:409-412.

Rorig B, Klausa G, Sutor B (1996) Intracellular acidification reduced gap junctional coupling between immature rat neocortical pyramidal neurones. J Physiol (Lond) 490:31-49.

Ross FM, Gwyn P, Spanswick D, Davies SN (2000) Carbenoxolone depresses spontaneous epileptiform activity in the CA1 region of rat hippocampal slices. Neuroscience 100:789-796.

Rozental R, Campos de Carvalho AA, Spray DC (2000) Nervous system diseases involving gap junctions. Brain Res Rev 32:189-191.

Rozental R, Srinivas M, Spray DC (2001) How to close a gap junction channel. In: Methods in molecular biology, Vol 154: connexin methods and protocols (Bruzzone R, Guiaume C, eds), pp 447-476. Totowa, NJ: Humana.

Ruiz-Meana M, Garcia-Dorado D, Hofstaetter B, Piper HM, Soler-Soler J (1999) Propagation of cardiomyocyte hypercontracture by passage of $\mathrm{Na}^{+}$through gap junctions. Circ Res 85:280-287.

Saito R, Graf R, Hubel K, Fujita T, Rosner G, Heiss WD (1997) Reduction of infarct volume by halothane: effect on cerebral blood flow or perifocal spreading depression-like depolarisations. J Cereb Blood Flow Metab 17:857-864.

Scemes E, Spray DC (1998) Increased intercellular communication in mouse astrocytes exposed to hypo-osmotic shocks. Glia 24:74-84.
Siesjo B (1993) Basic mechanisms of traumatic brain damage. Ann Emerg Med 22:959-969.

Siushansian R, Cechetto DF, Bechberger JF, Hachinski V, Naus CCG (2002) Connexin43 null mutation increases infarct size after stroke. J Comp Neurol, in press.

Spray DC, Dermietzel R (1996) Gap junctions in the nervous system: an introduction. In: Gap junctions in the nervous system, pp 1-8. Austin, TX: RG Landes.

Spray DC, Harris AL, Bennet MVL (1981) Gap junctional conductance is a simple and sensitive function of intracellular $\mathrm{pH}$. Science 211:712-715.

Stein CA (1998) How to design an antisense oligonucleotide experiment: a consensus approach. Antisense Nucleic Acid Drug Dev 8:129-132.

Sullivan PG, Keller JN, Mattson MP, Scheff SW (1998) Traumatic brain injury alters synaptic homeostasis: implications for impaired mitochondrial and transport function. J Neurotrauma 15:789-798.

Teubner B, Odermatt B, Guldenagel M, Sohl G, Degen J, Bukauskas F, Kronengold J, Verselis VK, Jung YT, Kozak CA, Schilling K, Willecke $\mathrm{K}$ (2001) Functional expression of the new gap junction gene connexin 47 transcribed in mouse brain and spinal cord neurons. J Neurosci 21:1117-1126.

Trosko JE, Chang C-C, Upham B, Wilson M (1998) Epigenic toxicology as toxicant-induced changes in intracellular signalling leading to altered gap junctional intercellular communication. Toxicol Lett 102-103:71-78.

Wade MH, Trosko JE, Schindler M (1986) A fluorescence photobleaching assay of gap junction mediated communication between human cells. Science 232:525-528.

Weber JT, Rzigalinski BA, Ellis EF (2001) Traumatic injury of cortical neurons causes changes in intracellular calcium stores and capacitive calcium influx. J Biol Chem 276:1800-1807.

Yuste R, Nelson DA, Rubin WW, Katz LC (1995) Neuronal domains in developing neocortex: mechanisms of coactivation. Neuron 14:7-17. 